\title{
Análise do Desempenho do Modelo Weather Research and Forecasting (WRF) com Diferentes Esquemas de Microfísica e Camada Limite Planetária na Ilha Deception, Antártica
}

\author{
Alcimoni Nelci Comin ${ }^{1}$, Ronald Buss de Souza ${ }^{2}$, Otávio Costa Acevedo ${ }^{1}$, Vagner Anabor ${ }^{1}$ \\ ${ }^{1}$ Departamento de Física, Universidade Federal de Santa Maria, Santa Maria, RS, Brasil. \\ ${ }^{2}$ Centro Regional Sul, Instituto Nacional de Pesquisas Espaciais, Santa Maria, RS, Brasil.
}

Recebido:20/03/2015 - Aceito: 22/01/2016

\begin{abstract}
Resumo
Diferentes esquemas de CLP e microfísica do modelo WRF são comparados em uma pequena ilha na Antártica com um lago com atividade geotermal em seu interior. Dados coletados em uma torre micrometeorológica são comparados com o modelo para 3 dias de situações atmosféricas distintas: nebulosidade baixa, céu relativamente claro e a passagem de um ciclone sobre a ilha.Para a temperatura do ar, osdiferentes experimentos resultam num ciclo diário de menor amplitude que os observados. A variabilidade entre os esquemas é menor que $1{ }^{\circ} \mathrm{C}$, devido à influência da TSM e à sua diferente capacidade em reproduzir nebulosidade. Para o dia de céu claro, a previsão de radiação de onda curta depende fortemente do esquema microfísico utilizado e pouco dos esquemas de CLP. Para a radiação de onda longa os esquemas produzem resultados semelhantes, porém quando há ciclone atuando o esquema THOMPSON tem melhor desempenho que o WSM3.Para o vento zonal, a variabilidade entre os esquemas de CLP é geralmente maior ( $1 \mathrm{a} 3 \mathrm{~m} / \mathrm{s})$ que entre os de microfísica (menor que $1 \mathrm{~m} / \mathrm{s}$ ). O esquema WSM3 é, em geral, mais indicado para as previsões nos dias de ciclone. Para a componente meridional do vento observa-se pouca diferença entre os esquemas microfísicos e CLP.
\end{abstract}

Palavras-chave: WRF, Ilha Deception, esquemas de camada limite planetária e microfísica.

\section{Analysis of Weather Research and Forecasting (WRF) Model with Different Schemes Microphysics and Planetary Boundary Layer on the Island Deception, Antarctica}

\begin{abstract}
Different PBL and mycrophysics schemes in WRF model are compared for a small island in Antarctic with a geothermally active lake in its interior. Data collected by a micrometeorological tower are compared to the simulations for 3 days with distinct meteorological conditions: low cloudiness, clear sky and the passage of a cyclone over the island. For air temperature, the different experiments produced a daily cycle with smaller amplitude than in observations. The variability among schemes was less than $1^{\circ} \mathrm{C}$, mostly because of SST influence and their different capabilities of solving cloudiness. For the clear sky day, the short wave radiation forecast is largely dependent on the mycrophysics scheme used and not as much on the PBL ones, but for long wave radiation the schemes produced similar results. But when there is a cyclone acting, THOMPSON mycrophysics scheme performs better than WSM3. For the zonal wind, the variability among PBL schemes is generally larger (1-3 m/s) than among the mycrophysics ones (less than $1 \mathrm{~m} / \mathrm{s}$ ). WSM3 scheme is generally better suited for forecasts in cyclone days. For the meridional wind component, there is little difference among mycrophysics and PBL schemes.
\end{abstract}

Keywords: WRF, Deception Island, planetary boundary layer and microphysics schemes.

Autor de correspondência: Alcimoni Nelci Comin, email: alcimoni.comin@gmail.com. 


\section{Introdução}

No continente antártico, a circulação atmosférica é fortemente influenciada pela presença do gelo marinho e pelo gelo permanente presente nas altitudes acima de 3 quilômetros na maioria das áreas continentais (Monaghan et al., 2005). Na escala sazonal, a formação de gelo marinho e sua extensão sobre o Oceano Austral durante o inverno do hemisfério sul aumenta o albedo terrestre, sendo fator preponderante para a configuração do clima sazonal global e da frequência com que as frentes frias de origem polar e os ciclones se formem e se propaguem na direção do Oceano Atlântico Sul e da América do Sul, afetando o clima do Brasil. A superfície do continente antártico possui alto albedo e baixas quantidades de aerossóis, o que resulta em diferentes interações da radiação na atmosfera (Laine, 2008).

A disponibilização de dados meteorológicos de modelos de grande escala, como o Sistema de Previsão Global final (GFS-FNL) fornecido pelos Centros Nacionais de Previsão Ambiental dos Estados Unidos (National Centers for Environmental Prediction - NCEP) são de grande valia para inicializar e oferecer condições de contorno para modelos de menor escala geográfica como o Weather Research and Forecasting (WRF). Os dados do GFS-FNL são derivados de observações de sensoriamento remoto e de perfis observacionais de variáveis como a temperatura, umidade, velocidade e direção do vento. Os dados meteorológicos coletados pelos sensores instalados em uma torre são mais escassos em regiões de altas latitudes e, como uma alternativa, a maior parte das saídas do GFS-FNL são baseadas puramente em dados de sensoriamento remoto. Isso tornou indispensável que se validem, tanto para esses modelos globais como aqueles regionais forçados pelos primeiros, os esquemas numéricos de microfísica e de Camada Limite Planetária (CLP). Somente após esse procedimento é possível reproduzir padrões meteorológicos em diversas escalas espaciais de maneira simultânea.

Powers et al. (2007) simulam condições de ventos extremos com o modelo WRF em 15-16 de maio de 2004, na estação de McMurdo Antártica, com diferentes assimilações de dados no modelo WRF, como por exemplo, o Sistema Padrão de Previsão de Mesoescala da Antártica (AMPS), o MOD1, o MOD1_60 e o CTRL que não envolve assimilação de dados. Eles concluem que além do modelo subestimar as rajadas de vento, também apresenta um atraso para prever os picos máximos de vento. Este atraso varia de 2 a 6 horas, dependendo da assimilação de dados. Além disso a previsão da trajetória do ciclone é deslocada da posição real. Dentro do contexto do AMPS, o modelo WRF é geralmente rodado com baixa resolução (90,30 e $10 \mathrm{~km})$. Somente nas regiões de McMurdo e Ilha de Ross é rodado com mais alta resolução $(3,3$ ou $2,2 \mathrm{~km})$. Cassano et al. (2011) utilizam sete configurações diferentes do modelo WRF em simulações no Ártico para as variáveis pressão atmosférica, altura geopotencial e precipitação, e concluem que para todas as configurações se verificam grandes erros na simulação da circulação no Pacífico Norte. Bromwich e Cassano (2000) identificam que os modelos globais para a região da Antártica possuem resoluções horizontais inadequadas: i) para resolver os padrões de mesoescala de curto prazo (6-24 horas); ii) para representação das propriedades físicas únicas da troposfera e da camada limite da Antártica e iii) pobre representação da topografia e dos padrões atmosféricos.

A CLP é a camada da atmosfera mais próxima do solo que é fortemente afetada pelo aquecimento diário, umidade e transferência de momento para a superfície. À noite, com a diminuição da temperatura, a parte superior da CLP é mais baixa do que durante o dia e atinge a extensão máxima à tarde. Sobre o oceano, o ciclo diário CLP é mais fraca, inexistente ou revertida (Bretherton et al., 2004). A modelagem do ciclo diário da CLP requer simulações precisas de fluxos sub-diário de calor, umidade e momentum (Yver et al., 2013). O WRF utiliza parametrizações físicas para representar radiações de ondas longa e curta, fluxos turbulentos na superfície, CLP, microfísica das nuvens e nuvens convectivas (Cassano et al., 2011).

Estes esquemas de CLP e microfísica podem afetar diretamente a previsão das variáveis meteorológicas testadas aqui, frente a diversas situações de nebulosidade e velocidade dos ventos. Alguns esquemas podem simular melhor para uma determinada condição meteorológica. Por exemplo, há centenas de voos anualmente que levam pesquisadores para a Antártica (Powers et al., 2003), e necessitam de informações meteorológicas com certo grau de precisão para pouso e decolagem. Dados de velocidade dos ventos e condições de nevoeiros na pista são indispensáveis. Alguns esquemas de CLP têm maior sensibilidade para prever nebulosidade estratiforme (por exemplo, nevoeiro) e outros para prever melhor a velocidade ou rajada dos ventos em tempo próximo do real.

Recentemente, muitos estudos têm focado em simular variáveis atmosféricas sobre as regiões polares a partir de uma perspectiva regional (Bromwich et al., 2009; Wilson, 2011; Hines et al., 2011; Bromwich et al., 2013). Tais simulações são realizadas sobre os domínios regionais, incluindo grandes áreas dos círculos polares. Este estudo, apesar de ter objetivos gerais semelhantes, foca em uma perspectiva local durante a passagens de sistemas ciclônicos. Não há estudos que mostram como modelos, tais como WRF são capazes de representar a variabilidade detalhada dos parâmetros atmosféricas em uma escala tão pequena quanto a da Ilha Deception. Esta é, portanto, a principal motivação do estudo. Hines e Bromwich (2008) consideram o WRF como um modelo no estado da arte para modelagem regional, desenvolvendo e testando o mesmo para uma previsão polar de última geração. Os autores consideram que novas otimizações do modelo são especialmente necessárias para uma melhor parametrização da ca- 
mada limite, da física de nuvens e de neve, assim como para melhor simular o pacote de gelo marinho.

Da mesma forma proposta por Hines e Bromwich (2008) para uma região da Groenlândia, o trabalho apresentado aqui tem como objetivo principal avaliar diferentes versões da física do modelo WRF num domínio regional centrado na Ilha Deception, arquipélago das Shetland do Sul, Antártica, e comparar os diferentes desempenhos de previsão de tempo desse modelo com dados observacionais coletados na Ilha entre os dias 20 e 22 de março de 2013, durante a passagem de um sistema ciclônico na região. Vários esquemas de CLP e microfísica são avaliados nas simulações, usando as condições de contorno GFS-FNL (final). Os esquemas de CLP podem afetar a velocidade do vento quando este é de fraca intensidade, reduzindo-o devido à rugosidade da superfície. Em uma atmosfera mais instável, existe uma elevada taxa de mistura vertical, neste caso, a velocidade do vento aumenta em níveis baixos (Cheng et al., 2013). Isso interfere na taxa de transporte de umidade para a atmosfera, além de interferir nas variáveis de temperatura, pressão do ar, radiação de ondas curta e longa, que são também investigados neste estudo através das simulações WRF.

Gibbs et al. (2011), Shin e Hong (2011) e Yver et al. (2013), por exemplo, apresentam estudos objetivando melhorar o desempenho dos esquemas de CLP. Os diversos autores, em geral, concluem que não há desempenho melhor de um determinado esquema sobre os outros em todas as variáveis sinóticas. Ao contrário do estudo apresentado aqui, não há ao nosso conhecimento outros estudos comparando, ao mesmo tempo, todos esses esquemas de CLP com dois esquemas de microfísica distintos.

De acordo com Hines e Bromwich (2008), o fato de que as regiões polares estão sujeitas ao efeito climático da "amplificação polar" devido ao feedback albedo-gelo marinho, a quantificação dos processos físicos ativos nessas regiões realizada através de experimentos numéricos com modelos de alta resolução espacial e boa topografia é uma maneira eficiente de tratar o problema. Os autores acrescentam que as regiões polares não são priorizadas no desenvolvimento das parametrizações em modelos numéricos e na Antártica, em especial, a sensibilidade das simulações é persistentemente corrompida pela excessiva cobertura de nuvens.

Apesar do PROANTAR ser um programa de Estado brasileiro existente há mais de 30 anos, não existe ainda um programa de otimização de modelos numéricos de previsão de tempo para o ambiente antártico a serem rodados operacionalmente no Brasil. Powers et al. (2012) reportam o sucesso da implementação da versão otimizada para ambiente polar do WRF (Polar WRF) para suportar o Programa Antártico americano há mais de dez anos. Os resultados apresentados nesse estudo são inéditos sob esse ponto de vista e espera-se contribuir, no futuro, para a implemen- tação do WRF com otimização polar em benefício do PROANTAR.

Devido à escassez de observações meteorológicas em alta frequência na região antártica de interesse do PROANTAR e também à falta de modelos de previsão de tempo operando em tempo real para essa área, as atividades humanas, especialmente brasileira, são limitadas por questões de logística e segurança. O Brasil está presente na Antártica há mais de 30 anos, atuando permanentemente na região norte da Península Antártica e do arquipélago das Shetland do Sul. A coleta operacional de dados meteorológicos em alta frequência, associada à implementação de um modelo de previsão do tempo como o WRF na região de interesse do Brasil na Antártica poderia elevar o padrão das ações brasileiras na Antártica a um nível internacional e contribuir para futuras iniciativas científicas, logísticas e ambientais brasileiras no meio ambiente antártico.

\section{2. Área de Estudo}

Ruhl et al. (2003) e Smith Jr. et al. (2003) descrevem a Ilha Deception, localizada em 6258'66" S e 60³9'56" W como um vulcão ativo sazonalmente coberto por gelo. A Ilha faz parte do arquipélago das Shetland do Sul, sendo uma cratera inundada que mantém um corpo de água interior com uma abertura estreita para o Estreito de Bransfield. A conexão entre as águas interiores e exteriores da Ilha se dá através dos Foles de Netuno, que tem cerca de $550 \mathrm{~m}$ de largura no seu ponto mais estreito e cerca de $11 \mathrm{~m}$ de profundidade no seu ponto mais raso. A baía interior da cratera é conhecida como Baía de Port Foster, a qual possui dimensões de $9,8 \times 5,7 \mathrm{~km}$.

Segundo Smith Jr. et al. (2003), as condições meteorológicas em Port Foster tendem a ser tipicamente semelhantes àquelas encontradas em outras regiões do Estreito de Bransfield. Durante o período de seu estudo entre março de 1999 e novembro de 2000, as temperaturas do ar em Port Foster variaram aproximadamente entre $-13{ }^{\circ} \mathrm{C}$ e $3{ }^{\circ} \mathrm{C}$ dependendo da estação do ano. Os ventos na superfície $(2 \mathrm{~m})$ variaram entre cerca de zero e $47 \mathrm{~m} / \mathrm{s}$, predominando na direção sudoeste. Smith Jr. et al. (2003), no entanto, descrevem que as intensidades de vento medidas em Port Foster foram consideravelmente diferentes daquelas medidas na mesma época na estação Bellingshausen, na Ilha do Rei George, ao norte da Ilha Deception. Durante o período de estudo, a cobertura de nuvens na Ilha Deception foi persistente por $50 \%$ do tempo. A precipitação atingiu uma grande área e por muitos dias a visibilidade foi tão baixa a ponto de inviabilizar a avaliação das condições de gelo e neve através de uma câmera digital. A tabela 1 mostra os valores médios dos dados observados e simulados pelo modelo WRF que são discutidos neste trabalho. 
Tabela 1 - Médias dos dados observados e simulados pelos diversos esquemas de CLP e de microfísica. Os números fora dos parênteses são para o esquema microfísico WSM3 e entre parênteses para o esquema microfísico THOMPSON, para as variáveis: temperatura do ar (Tar), radiação de onda curta incidente (ROC), radiação de onda longa incidente (ROL), pressão atmosférica (PA) e as componentes zonal (U) e meridional (V) da velocidade do vento.

\begin{tabular}{lcccccc}
\hline WSM3 (THOMPSON) & Tar $\left({ }^{\circ} \mathrm{C}\right)$ & ROC $\left(\mathrm{W} / \mathrm{m}^{2}\right)$ & ROL $\left(\mathrm{W} / \mathrm{m}^{2}\right)$ & $\mathrm{PA}(\mathrm{hPa})$ & $\mathrm{U}(\mathrm{m} / \mathrm{s})$ & $\mathrm{V}(\mathrm{m} / \mathrm{s})$ \\
\hline ACM & $1,4(1,3)$ & $38(51)$ & $287(289)$ & $971,3(971,4)$ & $0,03(0,01)$ & $-7,18(-6,89)$ \\
BOULAC & $1,5(1,7)$ & $45(52)$ & $286(295)$ & $971,4(971,3)$ & $1,24(1,38)$ & $-7,35(-6,90)$ \\
MYJ & $1,1(1,1)$ & $47(67)$ & $282(284)$ & $971,3(971,3)$ & $0,02(0,03)$ & $-6,78(-6,98)$ \\
MYNN2,5 & $1,4(1,5)$ & $40(56)$ & $287(288)$ & $971,3(971,3)$ & $-0,19(-0,2)$ & $-6,52(-6,76)$ \\
MYNN3 & $1,5(1,5)$ & $41(57)$ & $287(287)$ & $971,3(971,3)$ & $0,08(0,01)$ & $-6,66(-6,78)$ \\
Observado & 2,2 & 31 & 313 & 971,7 & $-0,24$ & $-5,05$ \\
\hline
\end{tabular}

\section{O Modelo WRF: Breve Descrição e Esquemas de Parametrização}

O WRF é desenvolvido para a pesquisa, previsão do tempo, modelagem da qualidade do ar, modelagens climáticas em escala regional, pesquisa de furacões entre outras (Skamarock et al., 2008). O modelo contém diferentes opções para os esquemas de parametrização. Nesse trabalho, diferentes simulações são realizadas utilizando-se seis esquemas de CLP distintos, a saber:

Bougeault-Lacarrère (BOULAC): Esquema de CLP proposto por Bougeault e Lacarrère (1989) com opção para energia cinética turbulenta (ECT). Este esquema parametriza as turbulências induzida pela topografia para representar os casos de não homogeneidade horizontal. O esquema é baseado na equação prognóstica de ECT com uma ordem e meia de fechamento. Segundo o autor a ECT em um modelo de escala meso beta permite boas previsões da localização e intensidade da turbulência de ar claro em regiões onde o fluxo passa sobre uma orografia íngreme. Esse sucesso se deve a dois aspectos: i) a boa dinâmica do modelo com resolução vertical suficiente para resolver a propagação das ondas internas e resolução horizontal para resolver as características topográficas; ii) a maior parte dos fluxos na atmosfera a escala de comprimento dos turbilhões é determinada principalmente pela resistência do deslocamento vertical devido à estabilidade estática.

Mellor-Yamada-Janjic (MYJ): Esquema de CLP que resolve a ECT de produção/dissipação com uma parametrização dos efeitos da CLP, proposto por Janjic (2002). A equação diferencial de produção/dissipação é resolvida de forma iterativa durante um intervalo de tempo. Em cada iteração, a equação diferencial é obtida por linearização em torno da solução a partir da iteração anterior. Duas iterações parecem ser suficientes para a exatidão e o custo computacional é menor. $\mathrm{O}$ esquema inclui parametrizações na sub-camada viscosa. Sobre a água a sub-camada viscosa é parametrizada explicitamente. Sobre o solo, os efeitos da sub-camada viscosa são considerados de acordo com a altura do comprimento de rugosidade influenciando na temperatura e umidade como proposto por Zilitinkevich (1995).
Quasi-Normal Scale Elimination (QNSE): Este esquema proposto por Sukoriansky et al. (2005) é o mais adequado sob condições de estabilidade, como em inversões de temperatura onde a maioria dos esquemas de CLP tem problemas. $\mathrm{O}$ esquema baseia-se em um mapeamento quase Gaussiano nos campos de velocidade e temperatura usando equações de Langevin. Com o aumento da estratificação, a viscosidade vertical e difusividade são suprimidas enquanto os seus homólogos horizontais são reforçados. O esquema é utilizado para determinar várias características espectrais dos fluxos turbulentos na camada estavelmente estratificada que é responsável pela acumulação de energia nas componentes horizontais, à custa da redução da energia na vertical.

Mellor-Yamada Nakanishi e Niino Nível 3 (MYNN3): Este esquema proposto por Nakanishi e Niino (2004) contém uma extensão da ECT de MYJ com uma formulação mais complexa para calcular os fluxos turbulentos. Os fluxos turbulentos na superfície são determinados a partir da teoria Monin-Obukhov. A temperatura na superfície é determinado pelo método força restore e o fluxo de calor no solo é obtido a partir da equação do balanço de energia na superfície. O modelo reproduz a ocorrência de instabilidade Kelvin-Helmholtz e oscilações periódicas devido ao seu ciclo de energia.

Mellor-Yamada Nakanishi e Niino Nível 2.5 (MYNN2.5): Versão simplificada do sistema MYNN3 para reduzir o custo computacional, proposto por Nakanishi e Niino (2006).

Asymmetric Convective Model (ACM): Esquema de CLP que considera uma mistura de fechamento não local dos fluxos acima da camada limite convectiva (CLC) e uma mistura local abaixo, proposto por Pleim e Chang (1992). O modelo baseia-se no conceito de que o transporte vertical dentro da CLC é totalmente assimétrico. O transporte para cima por plumas flutuantes, originários da camada superficial, é simulada através da mistura de camada inferior do modelo diretamente para todas as outras camadas do transporte descendente da CLC. O modelo é capaz de simular realisticamente o transporte vertical a partir das fontes em qualquer altura dentro ou acima da CLC. 
Os dois esquemas de microfísica utilizados aqui são: (i) O esquema WSM3 (WRF Single Moment 3-class Scheme), proposto por Hong et al. (2004), que é um esquema simples eficiente com gelo e neve e (ii) $\mathrm{O}$ esquema THOMPSON, proposto por Thompson et al. (2004), que possui processos de gelo, neve e graupel (neve precipitável na forma esférica, não em flocos) que são adequados para simulações de alta resolução.

\section{Materiais e Métodos}

Como parte do projeto INTERCEPTION (Interações entre o Oceano, Zona Costeira e Atmosfera em MicroEscala na Ilha Deception, Arquipélago das Shetland do Sul, Antártica), fomentado pelo PROANTAR, uma torre micrometeorológica foi instalada nas proximidades da Estação Antártica Espanhola Gabriel de Castilla (EAEGC), na Ilha Deception na posição $62^{\circ} 58^{\prime} 66^{\prime \prime}$ S e $60^{\circ} 39^{\prime} 56^{\prime \prime} \mathrm{W}$. A torre micrometeorológica, após sua completa montagem e testes, ficou em operação no período entre os dias 20 e 23 de março de 2013. Os dados observacionais utilizados aqui são medições horárias obtidas pelos sensores instalados na torre micrometeorológica na Ilha Deception entre os dias 20 e 22 de março de 2013. As variáveis utilizadas são: a temperatura do ar (Tar), radiação de onda curta incidente (ROC), radiação de onda longa incidente (ROL) e pressão atmosférica (PA) ambos a 2 metros da superfície; e as componentes zonal (u) e meridional (v) da velocidade do vento ambos a 10 metros da superfície.

Para as simulações numéricas apresentadas aqui são utilizadas três grades aninhadas e concêntricas, centradas na Ilha Deception (Fig. 1). O domínio externo tem espa-

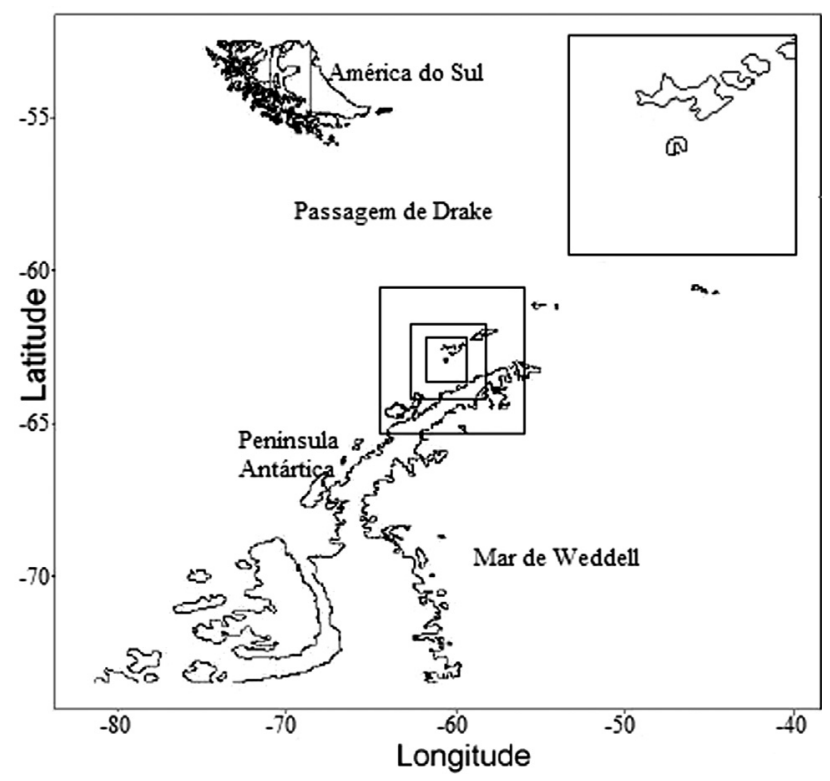

Figura 1 - Localização da Ilha Deception no arquipélago das Shetland do Sul, Antártica com as grades aninhadas do modelo WRF centradas na ilha. A direita detalhe da Ilha Deception mostrando a sua configuração em forma de ferradura e a Baía de Port Foster. çamento de grade de $9 \mathrm{~km}$ e 50 x 50 pontos de grade em cada direção horizontal. A primeira grade aninhada tem espaçamento de $3 \mathrm{~km}$ com 54 x 60 pontos na direção horizontal. A grade interna tem $1 \mathrm{~km}$ de espaçamento com $82 \times 86$ pontos na horizontal. Todas as grades utilizadas possuem 28 níveis na vertical. As condições iniciais e de contorno são fornecidos pelo GFS-FNL com $1^{\circ} \times 1^{\circ}$, disponíveis a cada 6 horas no sitio: (http://rda.ucar.edu/datasets/ds083.2/). No total são realizados 12 simulações, combinando-se os seis esquemas de CLP com os dois esquemas de microfísica.

\section{Análise Sinótica}

Para uma melhor interpretação dos resultados a serem discutidos aqui, as Figs. 2 e 3 mostram dados de análise do GFS-FNL com $1^{0} \times 1^{0}$ de resolução para a pressão ao nível médio do mar e ventos a $10 \mathrm{~m}$ da superfície, para o período entre 20 e 22 de março de 2013. Durante esse período, a região desse estudo está sob o predomínio de uma área de baixa pressão em superfície (Fig. 2) que se aproxima da região norte da Península Antártica e sobre o arquipélago das Shetland do Sul. No dia 20 de março, a Ilha Deception está sob a influência da borda leste de um sistema ciclônico, o qual o passa sobre a península Antártica (Fig. 2). Neste dia os ventos variam de nordeste a norte (Fig. 3) com o aumento de magnitude. No dia 21 , há a aproximação de outro sistema ciclônico na Ilha, porém este passa ao sul sobre a península, com ventos predominantes de noroeste sobre a Ilha (Fig. 3). Para este dia também é processada uma imagem no canal infravermelho do satélite GOES-12 (Fig. 4) para a temperatura de topo de nuvens mostrando a alta nebulosidade (convecção profunda em uma ampla região) que passa atuar sobre a Ilha Deception, às 17:45 UTC, associada ao sistema ciclônico. No dia 22, o ciclone passa a atuar sobre a Ilha (Fig. 2), e o vento (Fig. 3), muda de direção de noroeste para norte-nordeste.

\section{Resultados e Discussão}

Os resultados das figuras apresentados nesta seção referem-se a saída do modelo com resolução de $1 \mathrm{~km}$. A Fig. 5 apresenta os dados observacionais e a Tar modelada para $2 \mathrm{~m}$ de altura com os seis diferentes esquemas de parametrização de CLP e os esquemas de microfísica WSM3 e THOMPSON. A Fig. 5 também apresenta os resultados das análises GFS-FNL para Tar. Os diferentes experimentos WSM3 resultam num ciclo diário de menor amplitude do que aquela vista nos dados observados. Isso é especialmente visível no dia 20 próximo às $15 \mathrm{UTC}$, onde a temperatura máxima (observada) do ar chegou a $4,8^{\circ} \mathrm{C}$, com amplitude diária de $2,8{ }^{\circ} \mathrm{C}$. No experimento BOULAC, que é a melhor simulação do ponto de vista estatístico (Tabela 2, raiz do erro quadrático médio $(\mathrm{REQM})=1,32^{\circ} \mathrm{C}$ e coeficiente de correlação de 0,81 ), a Tar nesse horário é de $2,5^{\circ} \mathrm{C}$ e a amplitude do ciclo diário é de $1,8{ }^{\circ} \mathrm{C}$. A 


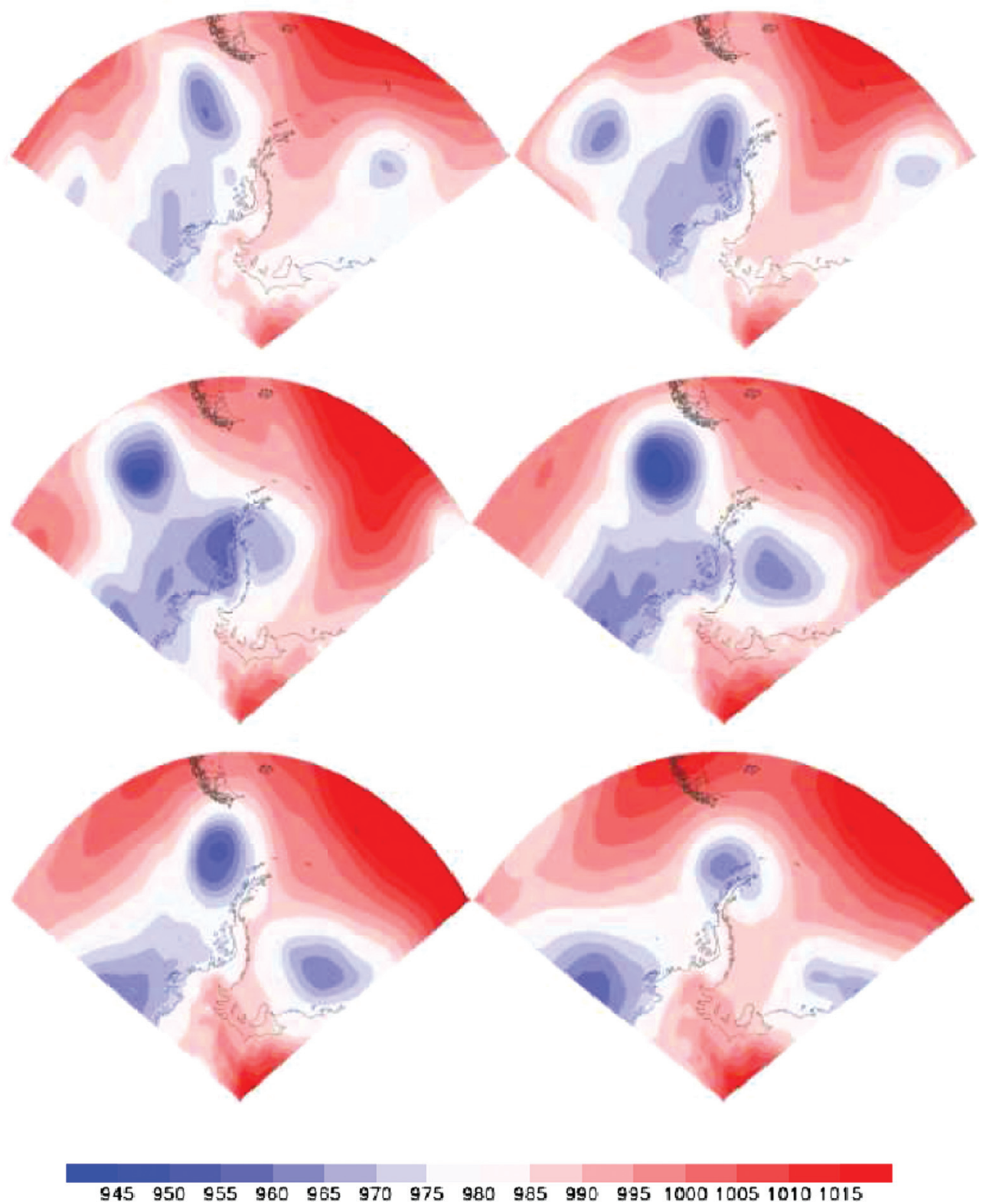

Figura 2 - Evolução dos campos de pressão atmosférica ao nível médio do mar (hPa) em torno da península Antártica para os dias 20, 21 e 22 de março de 2013 (de cima para baixo), às 00 UTC (esquerda) e 12 UTC (direita).

simulação BOULAC com o esquema THOMPSON é muito semelhante à sua variante com o esquema WSM3, no entanto no primeiro ocorre um pico de Tar inesperado de $6,8^{\circ} \mathrm{C}$ aproximadamente às 23 UTC do dia 20 de março.

A Tabela 1 mostra a Tar média para todo o período, observa-se uma subestimativa de $1,1{ }^{\circ} \mathrm{C}$ no MYJ para ambos os esquemas microfísicos (WSM3 e THOMPSON) em relação o observado, chegando a $0,5^{\circ} \mathrm{C}$ no esquema de BOULAC (THOMPSON). A Tabela 2 demonstra que, para as simulações de Tar, as maiores REQM são resultantes da aplicação do esquema THOMPSON para todas as variantes de CLP, exceto para MYNN2.5 onde a REQM para o esquema WSM3 é levemente superior ao esquema THOMPSON $\left(1,45{ }^{\circ} \mathrm{C}\right.$ contra $1,43{ }^{\circ} \mathrm{C}$, respectivamente).
Os coeficientes de correlação para a Tar observada vs. a simulada (Tabela 3), com exceção daquele da simulação BOULAC, esquema THOMPSON ( 0,51 - provavelmente devido à presença do pico de Tar de $6,8^{\circ} \mathrm{C}$ descrito anteriormente), são sempre altos, superiores a 0,7 . O maior coeficiente de correlação $(0,82)$ é obtido entre a Tar observada e a simulada com o esquema QNSE na opção THOMPSON.

Conforme descrito na análise sinótica, no dia 21, há aproximação de um sistema ciclônico (Fig. 2), e as diferentes simulações do modelo WRF têm uma menor amplitude de queda de temperatura do ar do que o observado pelos sensores instalados na torre micrometeorológica. A Tar observada diminui de $5{ }^{\circ} \mathrm{C}$ às 15 UTC do dia 20/02/2013 

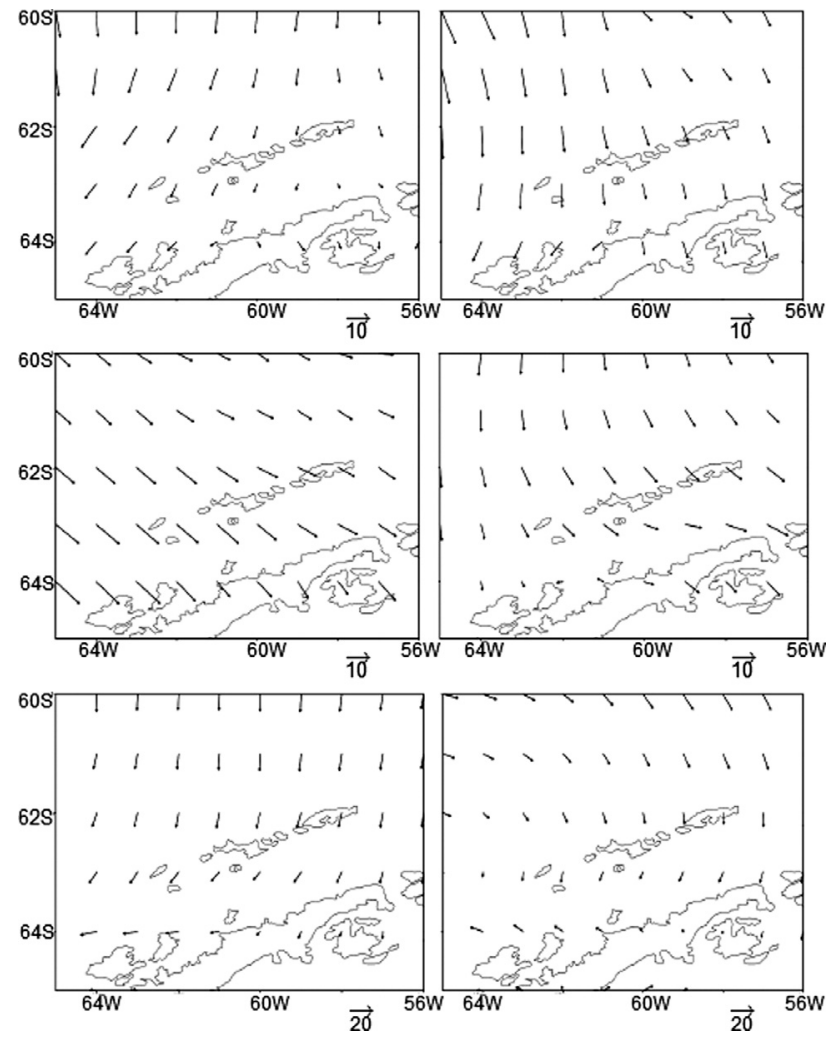

Figura 3 - Evolução dos campos de direção e intensidade do vento em superfície na região do arquipélago das Shetland do Sul e península Antártica para os dias 20,21 e 22 de março de 2013 (de cima para baixo), às 00 UTC (esquerda) e 12 UTC (direita).

para $0,5^{\circ} \mathrm{C}$ às 12 UTC do dia $21 / 03 / 2013$, o que resulta numa taxa de resfriamento de $0,21{ }^{\circ} \mathrm{C} /$ hora. Nenhuma simulação realizada aqui acompanha essa taxa. A melhor aproximação é resultante da simulação BOULAC, esquema WSM3 onde, para o mesmo período referido acima, a taxa de resfriamento é de $0,05^{\circ} \mathrm{C} /$ hora (Tar simulada diminuiu de $2,5^{\circ} \mathrm{C}$ às 15 UTC do dia $20 / 02 / 2013$ para $1,5^{\circ} \mathrm{C}$ às 12 UTC do dia 21/03/2013). Nos dias 21 e 22, a sensibilidade entre os diferentes esquemas para a Tar é menos variável nas simulações (amplitude menor entre os esquemas) do que no dia 20. Após a aproximação do sistema ciclônico na Ilha Deception no dia 21/03/2013, a Tar observada atinge um pico de $4{ }^{\circ} \mathrm{C}$ às $18 \mathrm{UTC}$, que não é simulado em nenhuma das opções de CLP e microfísica do WRF testadas aqui. Um outro pico de Tar observada acontece no dia 22/03/2013 às 9 UTC, e esse sim parece ser bem representado, apesar de em menor amplitude e com retardo de tempo de cerca de 1 hora, pela diversas simulações.

Observa-se que o WRF, em todas as suas configurações testadas aqui para simular a Tar, assemelha-se aos dados originais do GFS-FNL. Apesar das boas correlações e baixos REQM, as séries simuladas não conseguem reproduzir a amplitude do ciclo diário local observado. Isto se deve, provavelmente, à influência da temperatura da superfície do mar (TSM) no interior da Ilha Deception, na Baía

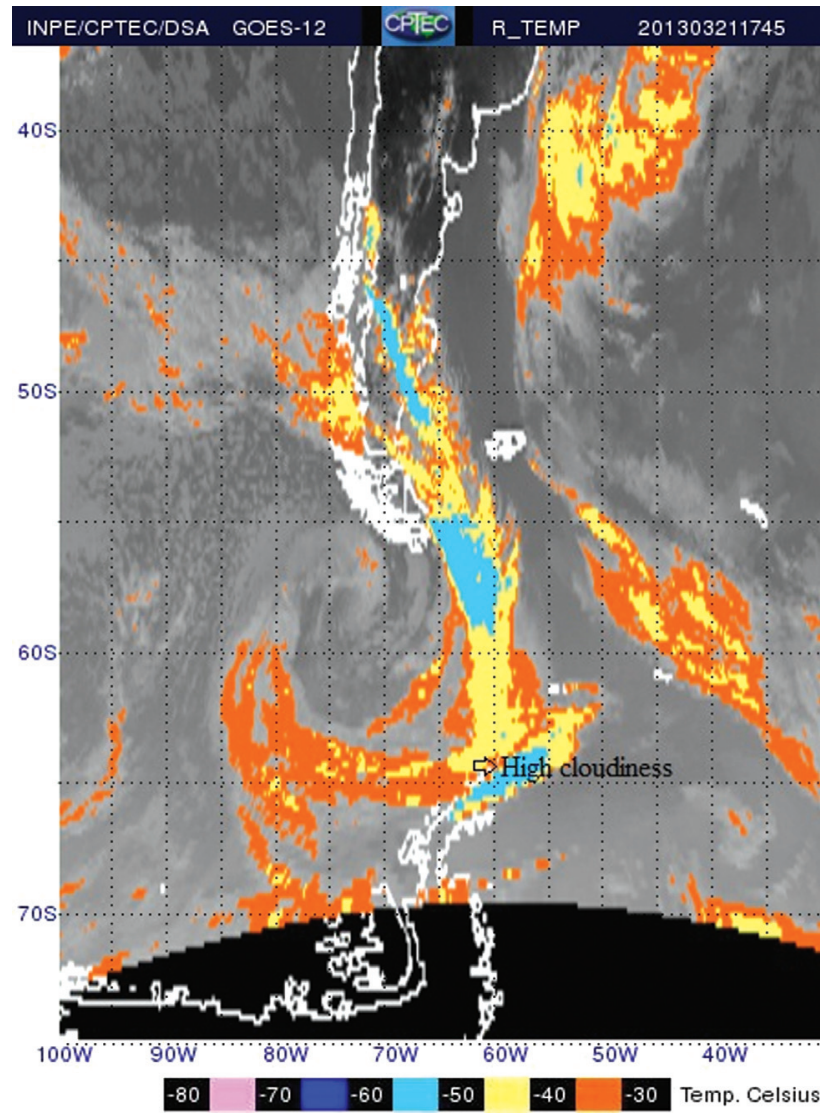

Figura 4 - Imagem no canal infravermelho do satélite GOES-12 processada para a temperatura de topo de nuvens mostrando uma nebulosidade alta sobre a Ilha Deception no dia 21 de março de 2013 às 17:45 UTC

de Port Foster. Considerando a elevada capacidade calorífica da água e o efeito do maior aquecimento da camada superior da água do mar ao meio dia, e na ausência de vento, especialmente descrito pela temperatura de pele (Donlon et al., 1999), a TSM pode imprimir um efeito local na Tar não levado em conta aqui. Nesses esquemas, durante a maior parte do período, a diferença da Tar entre as diferentes simulações é menor que $1{ }^{\circ} \mathrm{C}$, exceto às 16 UTC do dia 20 , quando a diferença chega $1,5^{\circ} \mathrm{C}$ no esquema microfísico WSM3. Já no esquema microfísico THOMPSON, a simulação de BOULAC às 23 UTC do dia 20, chega a $6{ }^{\circ} \mathrm{C}$ em comparação com as outras simulações. Essa diferença pequena (inferior à $1{ }^{\circ} \mathrm{C}$ ) está naturalmente associada à pouca variabilidade da TSM, que reduz a amplitude térmica diária observada, de forma que o maior valor registrado é de $4,8^{\circ} \mathrm{C}$.Assim, a variabilidade entre os esquemas simulados não é maior do que $1{ }^{\circ} \mathrm{C}$ e esta diferença de temperatura é associada à capacidade dos esquemas em reproduzir a nebulosidade estratiforme. Essa nebulosidade não é bem representada nos esquemas MYJ e QNSE, ocasionando erros nas radiações de ondas curta e longa e, consequentemente, na temperatura do ar (ver Tabelas 2 e 3 ). 


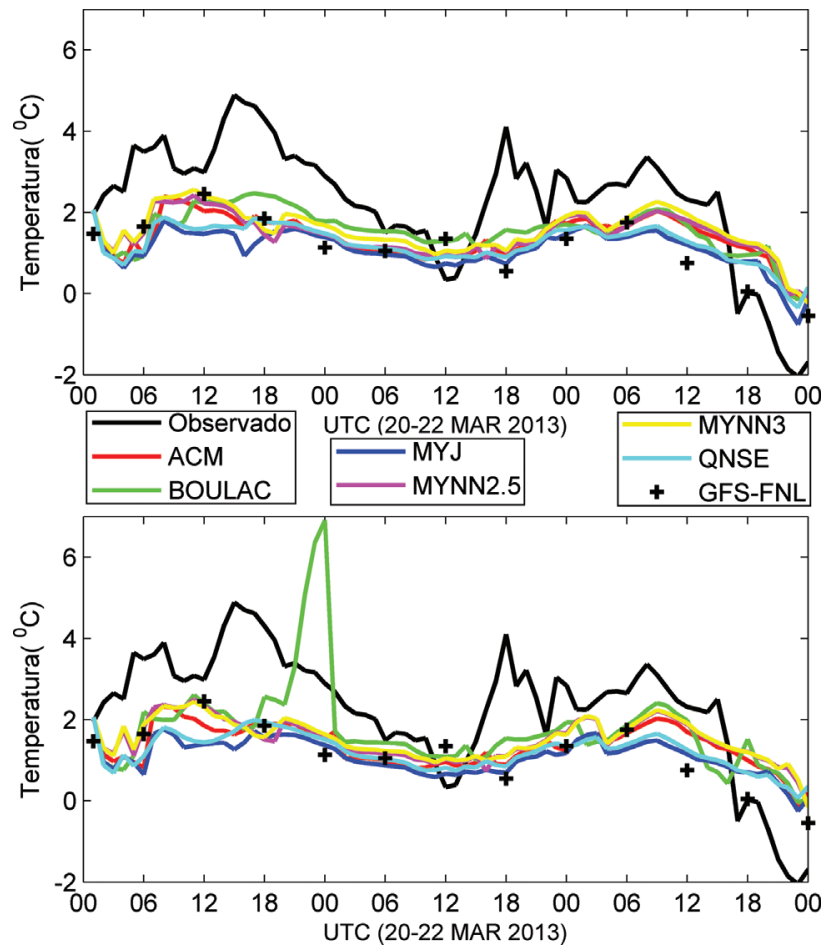

Figura 5 - Dados observacionais e a temperatura do ar modelada para $2 \mathrm{~m}$ de altura com os seis diferentes esquemas de parametrização de CLP e os esquemas de microfísica WSM3 (painel superior) e THOMPSON (painel inferior). As cruzes indicam as análises GFS-FNL para temperatura do ar.

A Fig. 6 mostra a radiação de onda curta incidente (ROC) na superfície modelada com todas as opções de parametrização de CLP e microfísica, usados juntamente com os dados observacionais da torre micrometeorológica.

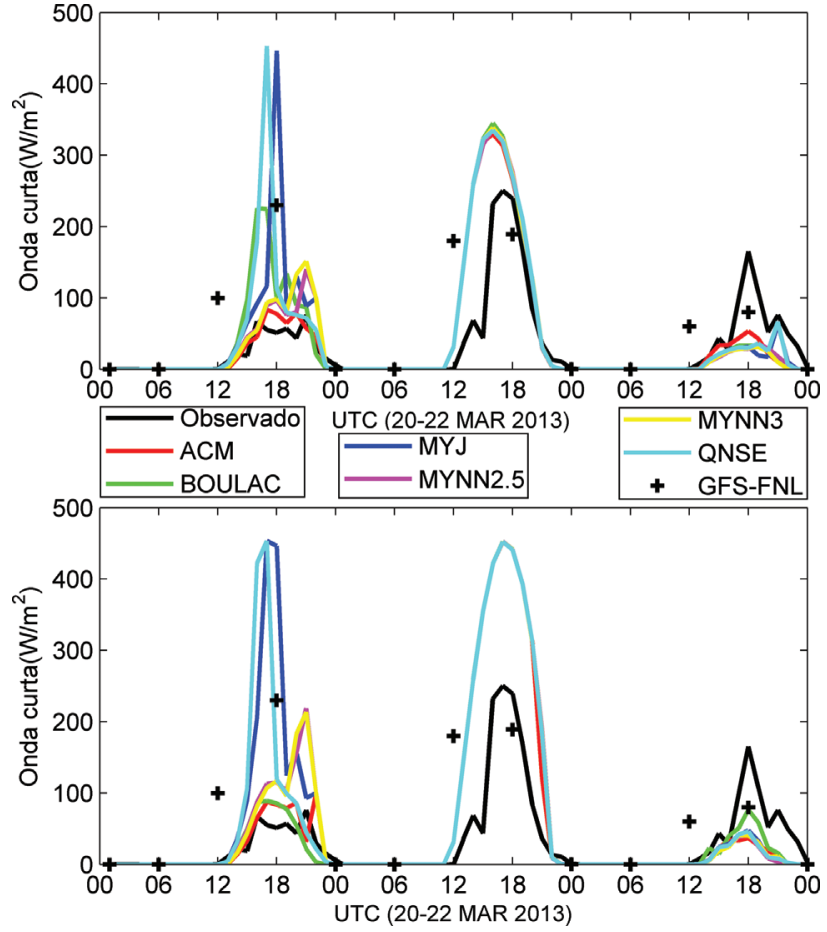

Figura 6 - O mesmo da Fig. 5, mas para a radiação de onda curta incidente.

Nota-se claramente que o modelo, em todas as suas opções de simulação, tende a superestimar os dados de ROC, exceto para o dia 22/03/2013. No dia 20, as simulações mostram picos entre $100 \mathrm{~W} / \mathrm{m}^{2}$ e $450 \mathrm{~W} / \mathrm{m}^{2}$, enquanto que o radiômetro instalado na torre mediu uma ROC de cerca de $80 \mathrm{~W} / \mathrm{m}^{2}$. A Tabela 2 mostra que REQM são altos e sempre maiores nas simulações THOMPSON, assim como o valor

Tabela 2 - O mesmo da Tabela 1, mas para a raiz do erro quadrático médio (REQM).

\begin{tabular}{lcccccc}
\hline WSM3 (THOMPSON) & Tar $\left({ }^{\circ} \mathrm{C}\right)$ & ROC $\left(\mathrm{W} / \mathrm{m}^{2}\right)$ & $\mathrm{ROL}\left(\mathrm{W} / \mathrm{m}^{2}\right)$ & $\mathrm{PA}(\mathrm{hPa})$ & $\mathrm{U}(\mathrm{m} / \mathrm{s})$ & $\mathrm{V}(\mathrm{m} / \mathrm{s})$ \\
\hline ACM & $1,47(1,50)$ & $48,9(76)$ & $42(42)$ & $1,55(1,59)$ & $4,13(4,15)$ & $4,37(4,17)$ \\
BOULAC & $1,32(1,46)$ & $59,1(76)$ & $43(39)$ & $1,54(1,51)$ & $4,28(4,57)$ & $4,51(4,61)$ \\
MYJ & $1,66(1,69)$ & $70(104)$ & $46(46)$ & $1,54(1,56)$ & $4,07(4,15)$ & $4,28(4,33)$ \\
MYNN2,5 & $1,45(1,43)$ & $51,6(81)$ & $43(44)$ & $1,53(1,57)$ & $4,51(4,40)$ & $4,10(4,20)$ \\
MYNN3 & $1,36(1,42)$ & $53,6(81)$ & $43(44)$ & $1,54(1,57)$ & $4,34(4,29)$ & $4,17(4,23)$ \\
QNSE & $1,54(1,59)$ & $70,1(100)$ & $46(43)$ & $1,58(1,56)$ & $4,17(4,12)$ & $4,31(4,40)$ \\
\hline
\end{tabular}

Tabela 3 - O mesmo da Tabela 1, mas para a correlação.

\begin{tabular}{lcccccc}
\hline WSM3 (THOMPSON) & Tar & ROC & ROL & PA & U & V \\
\hline ACM & $0,75(0,74)$ & $0,80(0,82)$ & $0,68(0,67)$ & $0,98(0,98)$ & $0,87(0,88)$ & $0,65(0,67)$ \\
BOULAC & $0,81(0,51)$ & $0,76(0,83)$ & $0,65(0,70)$ & $0,98(0,98)$ & $0,87(0,85)$ & $0,66(0,66)$ \\
MYJ & $0,78(0,77)$ & $0,70(0,75)$ & $0,65(0,60)$ & $0,98(0,98)$ & $0,88(0,87)$ & $0,65(0,64)$ \\
MYNN2,5 & $0,74(0,70)$ & $0,79(0,82)$ & $0,66(0,64)$ & $0,98(0,98)$ & $0,85(0,86)$ & $0,64(0,63)$ \\
MYNN3 & $0,75(0,72)$ & $0,78(0,82)$ & $0,66(0,64)$ & $0,98(0,98)$ & $0,86(0,87)$ & $0,64(0,63)$ \\
QNSE & $0,81(0,82)$ & $0,71(0,76)$ & $0,65(0,63)$ & $0,98(0,98)$ & $0,87(0,87)$ & $0,65(0,64)$ \\
\hline
\end{tabular}


médio simulado (Tabela 1). As simulações que apresentam melhores desempenhos estatísticos (Tabelas 1, 2 e 3) são ACM, MYNN2.5 e MYNN3 na opção WSM3. As simulações ACM, BOULAC, MYNN2.5 e MYNN3 apresentam os melhores desempenhos na opção THOMPSON (ver Tabelas 1,2 e 3 ). As diferenças entre a ROC simulada e a observada se dão provavelmente devido à presença de nebulosidade estratiforme que se estabeleceu sobre a Ilha Deception no dia 20/03/2013 (figura não mostrada). Os esquemas de QNSE, MYJ e BOULAC não representam adequadamente essa nebulosidade estratiforme com o esquema microfísico WSM3, já com o esquema microfísico THOMPSON os erros são ampliados no QNSE e MYJ, enquanto BOULAC passa a ser bem representado. Os outros esquemas parecem representar razoavelmente essa nebulosidade.

O dia 21 apresenta condições de céu claro, todas as simulações do WRF apresentam quase as mesmas estimativas para a ROC simulada, com uma superestimativa de cerca de $100 \mathrm{~W} / \mathrm{m}^{2}$ (esquema WSM3) e $200 \mathrm{~W} / \mathrm{m}^{2}$ (esquema THOMPSON) em relação aos dados reais. O modelo tende a simular uma atmosfera mais seca do que a observada. O esquema microfísico THOMPSON subestima mais a quantidade de umidade do que o esquema WSM3 de forma que os erros são ampliados em $100 \mathrm{~W} / \mathrm{m}^{2}$.

Para o dia 22/03/2013, com nebulosidade média e alta, a ROC é melhor representada. Esse último dia mostra dois picos, às 18 UTC e 22 UTC aproximadamente. O primeiro pico é capturado pelas diferentes simulações, porém o segundo só consegue ser representado pelas simulações MYJ e QNSE (na opção WSM3), isso indica que eles provavelmente são sensíveis à nebulosidade estabelecida no período entre 18 e 22 UTC.

Bromwich et al. (2013), rodando uma versão do Polar WRF para a região da estação antártica alemã de Neumayer $\left(70^{\circ} 40^{\prime} \mathrm{S}, 8^{\circ} 16^{\prime} \mathrm{W}\right)$, descrevem que há uma tendência de superestimativa da ROC e subestimativa ROL no WRF durante condições de céu claro. Os resultados descritos aqui para a ROC, apesar de não responderem bem ao sinal de amplitude do ciclo diário, são robustos do ponto de vista estatístico com coeficientes de correlação entre os dados observados e simulados (Tabela 3 ) sempre superiores a 0,7 .

A Fig. 7 mostra as simulações e as análises GFS-FNL e os dados observados de ROL na superfície. Em ambos os esquemas de microfísica (WSM3 e THOMPSON), as curvas de ROL simuladas para os dias 20 e 22, comportam-se de forma aproximada a curva de observações. No dia 21/03/2013, as simulações subestimam os dados observados entre $30 \mathrm{~W} / \mathrm{m}^{2}$ e $100 \mathrm{~W} / \mathrm{m}^{2}$ (dia e noite, respectivamente). Isso ocorre porque o modelo subestima a umidade real da atmosfera. Quando se tem nebulosidade média e alta (como em 22/3/2013), o esquema THOMPSON representa melhor a ROL do que o esquema WSM3. Em termos de representação (Fig. 5) a ROL apresenta um pico de radiação na simulação BOULAC, esquema THOMPSON encon-

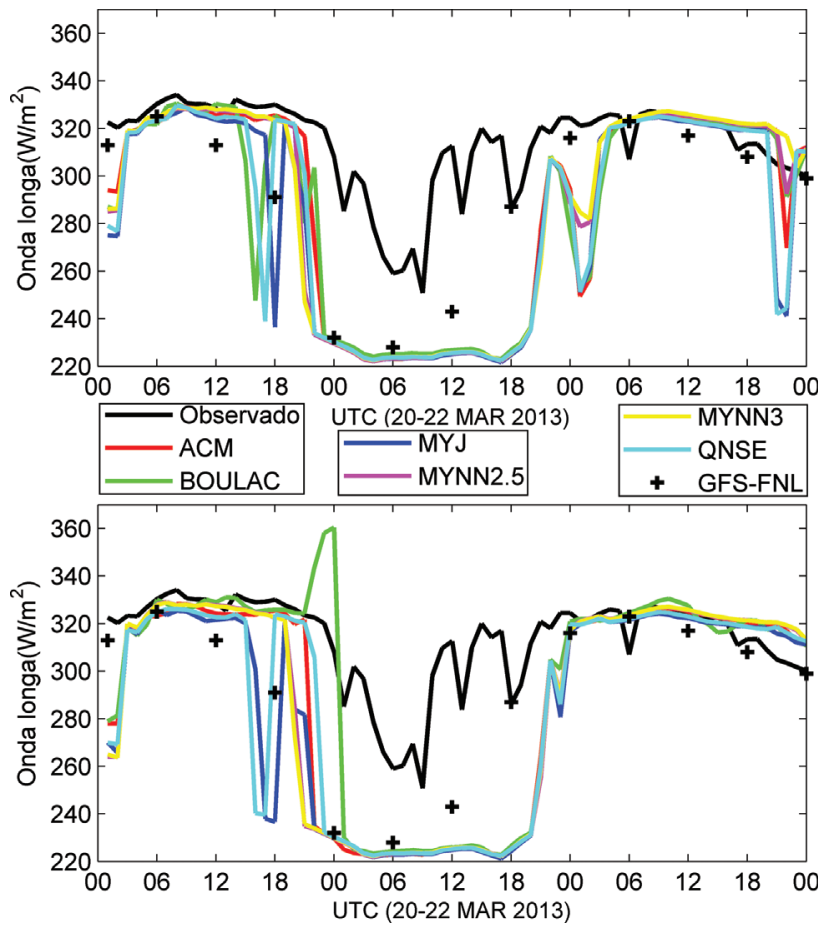

Figura 7 - O mesmo da Fig. 5, mas para a radiação de onda longa incidente.

trado nos resultados de Tar $=6,8^{\circ} \mathrm{C}$ aproximadamente às 23 UTC do dia 20 de março. A esse pico associa-se uma superestimativa na simulação do WRF de $40 \mathrm{~W} / \mathrm{m}^{2}$ em relação ao valor de $320 \mathrm{~W} / \mathrm{m}^{2}$ do dado observado. Pela Tabela 1 observa-se uma subestimativa média variando de $31 \mathrm{~W} / \mathrm{m}^{2}$ no esquema MYJ até $18 \mathrm{~W} / \mathrm{m}^{2}$ no esquema BOULAC, ambos na opção THOMPSON em relação ao dado observado. E pela (Tabela 2) a REQM varia de $39 \mathrm{~W} / \mathrm{m}^{2}$ a $46 \mathrm{~W} / \mathrm{m}^{2}$. Os coeficientes de correlação são, juntamente com aqueles relativos à componente meridional do vento (Tabela 3), os mais baixos encontrados nesse estudo, porém sempre superiores a 0,63 .

Nas simulações para ROL há, em geral, uma melhor representação quando se tem nebulosidade média, o que ocorre no dia 22/03/2013 (figura não mostrada). Para uma atmosfera com menor quantidade de nebulosidade, como observada durante o período da manhã do dia 21 (figura não mostrada), todos os experimentos apresentam o mesmo desempenho subestimando a umidade. Estudos realizados por Dong e Mace (2003), com o Polar WRF mostram que o modelo também não representa bem as nuvens stratus no Ártico. No dia 22, com a chegada do sistema ciclônico sobre a Ilha Deception, as simulações do modelo WRF reproduzem melhor a ROL. No dia 22 às 20-22 UTC, os diferentes experimentos de CLP (na opção WSM3) mostram picos não verificados nos dados reais, esses picos não ocorrem na opção THOMPSON. Nota-se também uma leve tendência de superestimativa da ROL simulada nas horas finais da série para todas as opções de CLP com a microfísica THOMPSON. Conclui-se que o modelo WRF tem 
dificuldade em estimar o balanço de energia na superfície, devido à má representação da cobertura de nuvens. Problema similar a esse é reportado por Bromwich et al. (2013) para o Polar WRF.

A Fig. 8 mostra as simulações da pressão atmosférica (PA) ao nível do mar pelos diferentes esquemas de CLP e microfísica do WRF em relação aos dados de análises GFS-FNL e observados. A PA é reproduzida de maneira bem satisfatória pelo WRF, pois essa apresenta pouca variabilidade em pequenas escalas de tempo. O ciclo da PA é mais dependente dos padrões meteorológicos de grande escala, repassados ao WRF pelo modelo global. Deve-se notar, no entanto, que tanto a amplitude do ciclo diário quanto as estimativas do WRF são mais próximas da realidade (vista pelos dados observados) que as análises do GFS-FNL que sempre tendem a superestimar os valores de $\mathrm{PA}$ entre cerca de $5 \mathrm{hPa}$ a $10 \mathrm{hPa}$.

Ainda com relação à $\mathrm{PA}$, todas as 12 simulações têm praticamente o mesmo desempenho, com valor médio próximo do observado (Tabela 1), baixos REQM entre $1,51 \mathrm{hPa}$ e 1,59 hPa (Tabela 2) e coeficientes de correlação de 0,98 (Tabela 3). A exceção de BOULAC no esquema microfísico THOMPSON que, novamente, apresenta um ponto fora da curva às 00 UTC do dia 21. Isso indica que os diferentes esquemas de CLP possuem a mesma sensibilidade para a pressão atmosférica. Os resultados são consistentes com aqueles apresentados por Hines et al. (2008) sobre a Groenlândia e Bromwich et al. (2009) sobre o Oceano Ártico, utilizando o Polar WRF. Hines et al. (2011), encontram coeficientes de correlação entre 0,95 a 0,99 para a

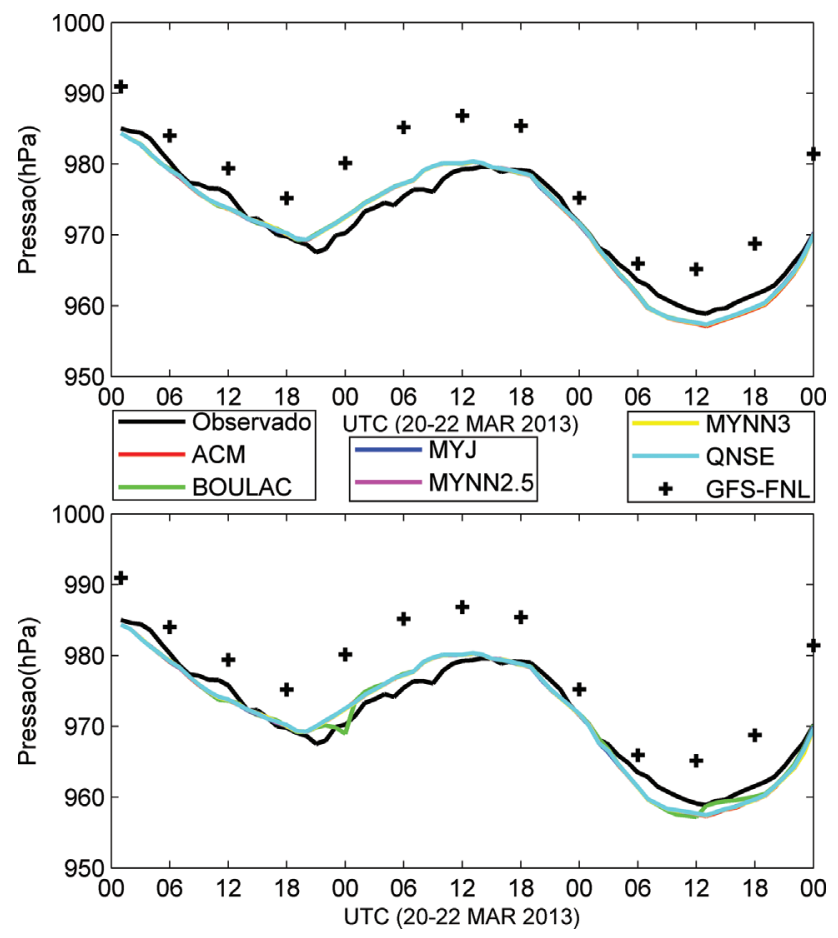

Figura 8 - O mesmo da Fig. 5, mas para a pressão atmosférica ao nível médio do mar. pressão atmosférica com o Polar WRF no Alasca. Dos resultados apresentados aqui conclui-se que, apesar da pressão atmosférica ser um forçante de grande escala atuando localmente e tendo seu ciclo independente das condições locais da Ilha Deception, as simulações WRF são válidas para melhor representar os valores reais de PA com respeito às análises GFS-FNL que os estão superestimando.

As Figs. 9 e 10 mostram as simulações, observações e análises GFS-FNL das componentes zonal (U) e meridional (V) da velocidade do vento em superfície. Todas as simulações WRF resolvem com certa precisão os ciclos diários do vento nas duas componentes, apesar da tendência de suavização de $\mathrm{U}$ e $\mathrm{V}$. Os valores médios para a componente zonal (ver Tabela 1) oscilam de $-0,2 \mathrm{~m} / \mathrm{s}$ à $1,38 \mathrm{~m} / \mathrm{s}$, valores próximos da média observada $-0,24 \mathrm{~m} / \mathrm{s}$. Já para o vento meridional (Tabela 1) há uma superestimativa em torno de $2 \mathrm{~m} / \mathrm{s}$. A REQM para as simulações de ambas componentes do vento é próximo a $4 \mathrm{~m} / \mathrm{s}$, enquanto que os coeficientes de correlação são maiores que 0,85 para $\mathrm{U}$ e menores que 0,67 para $\mathrm{V}$ (ver Tabelas 2 e 3 ).

Com a chegada do sistema ciclônico na Ilha, o vento zonal começa a aumentar de velocidade por volta das 16 UTC do dia 22/03/2013. Todos os esquemas de CLP têm um atraso para prever este aumento da velocidade do vento. Utilizando o esquema microfísico WSM3, os esquemas MYNN3 e MYJ simulam este aumento da velocidade do vento com diferenças de até 1 hora. Nos experimentos MYJ e QNSE, o aumento da velocidade é mostrado com um atraso de 3 horas em relação aos dados observados. Os outros experimentos têm resultados piores, com um atraso

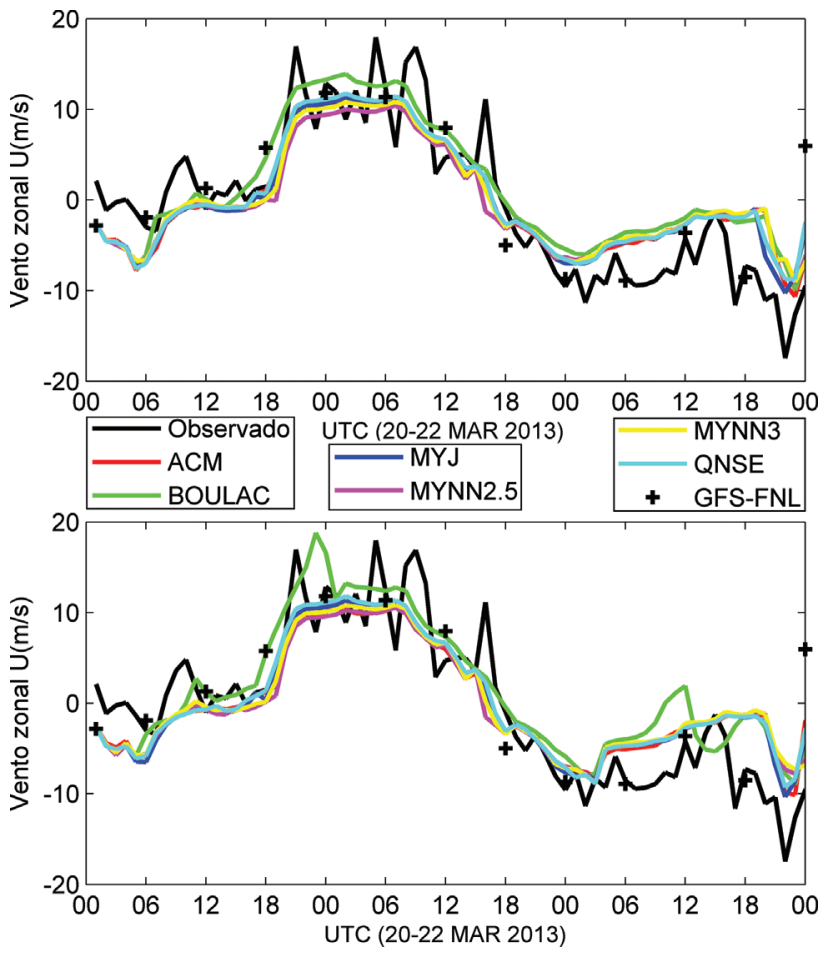

Figura 9 - O mesmo da Fig. 5, mas para a componente zonal do vento. 

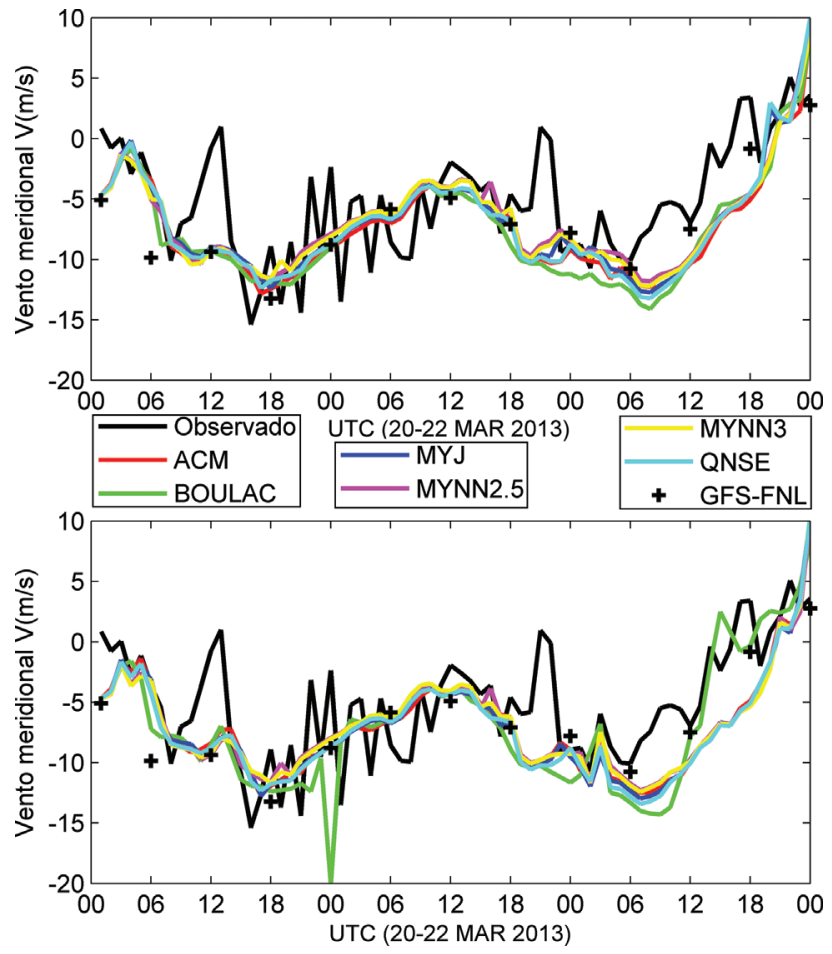

Figura 10 - O mesmo da Fig. 5, mas para componente meridional do vento.

de 4 horas. Esses resultados são similares aos encontrados por Cheng et al. (2013), que reportam um atraso para MYJ e QNSE de 3,33 e 2,83 horas, com o Polar WRF. Com os esquemas MYNN2.5 e MYNN3, o mesmo autor encontra atraso de 2,67 e 3,00 horas respectivamente. É importante destacar que em todos os experimentos há suavização e atraso no aumento da componente $\mathrm{U}$, mostrando que o modelo não tem sensibilidade para as flutuações do vento. A sensibilidade dos diferentes esquemas de CLP varia de 1 a $3 \mathrm{~m} / \mathrm{s}$ nas componentes zonal e meridional do vento, com maior sensibilidade para o esquema microfísico proposto por THOMPSON.

No esquema WSM3, os experimentos BOULAC e QNSE têm as maiores velocidades de vento $U$, enquanto os experimentos MYNN2.5 e MYNN3 têm a menor velocidade do vento. Ambos os experimentos MYJ e QNSE têm velocidade de vento mais próximo da observada, com menores REQM e altas correlações, sendo que MYJ apresenta o melhor resultado estatístico. A julgar pelas estatísticas dos erros do modelo, a velocidade do vento do experimento MYJ é mais próxima às observações durante o aumento do vento. Este resultado é confirmado pela Fig. 8 e pelas estatísticas horárias (tabela não mostrada) durante o período de aumento do vento. O experimento QNSE tem valores de velocidade do vento próximo ao de MYJ. Normalmente, este esquema é usado em condições de estabilidade (frio) e não é adequada em todas as situações (Cheng et al., 2013). Durante a passagem do sistema frontal (01 às 06 UTC do dia 20), a componente $\mathrm{V}$ do vento é bem representada pelo modelo, enquanto $\mathrm{U}$ é superestimada. $\mathrm{O}$ modelo captura corretamente o aumento da componente U às 18 UTC do dia 20, durante a aproximação do segundo sistema ciclônico, acompanhando bem a sua evolução até as 18 UTC do dia 21. Aproximadamente neste horário, com o estabelecimento do sistema ciclônico sob a Ilha (Fig. 4), o vento zonal muda de direção permanecendo assim até o final do período analisado. Quanto ao vento meridional (Fig. 10) e pelas estatísticas do modelo (Tabelas 1, 2 e 3) a sensibilidade entre os diferentes esquemas é muito semelhante. $\mathrm{O}$ experimento MYNN2.5 tem o valor médio mais próximo do observado e também o menor erro, enquanto ACM tem a melhor correlação com o esquema microfísico THOMPSON.

$\mathrm{O}$ atraso do aumento da componente $\mathrm{U}$ no dia 22 de março, é maior no esquema WSM3 do que no esquema THOMPSON. Porém as diferenças entre QNSE e MYNN3 no atraso da componente $\mathrm{U}$ são aproximadamente iguais. $\mathrm{O}$ vento meridional segue a mesma tendência do vento zonal com suavização das flutuações do vento, porém nesse não há atraso nas simulações nos períodos de aumento do vento.

Um esforço tem sido feito pela comunidade cientifica para otimizar a previsão numérica do tempo especificamente para os ventos (Cheng et al., 2013). Nas situações em que há predomínio de forçantes de grande escala, como na passagem de um sistema frontal intenso, essas condições não são bem representadas pelo modelo. Cheng et al. (2013) ressaltam a importância de um estudo mais detalhado para entender a sensibilidade do vento aos esquemas de parametrização de CLP. No presente trabalho, isso se caracteriza pela pouca diferença de desempenho do modelo para a simulação de vento, em relação aos diferentes esquemas utilizados. Essa situação é ainda mais evidente para a pressão atmosférica, que apresenta as mesmas correlações e erros entre os diferentes esquemas. Isso ocorre, porque esta é uma variável de grande escala com pequenas variabilidade em escalas locais, de forma que os diferentes esquemas de CLP e microfísica a simulam de maneira muito semelhante.

\section{Conclusões}

As simulações feitas com o WRF mostram que o modelo pode ser utilizado como uma ferramenta adequada, para fornecer informações próximas da realidade, dos parâmetros atmosféricos em escala local, em uma região de alta latitude, como da Ilha Deception. Podemos evidenciar isso, também pelos valores médios entre os dados simulados e observados (Tabela 1). A subestimativa média da Tar e ROL em BOULAC (THOMPSON) são de $0,5{ }^{\circ} \mathrm{C}$ e $18 \mathrm{~W} / \mathrm{m}^{2}$ respectivamente, a ROC superestima em $7 \mathrm{~W} / \mathrm{m}^{2}$ no esquema ACM (WSM3), a PA é representada quase que perfeitamente por todos os esquemas e as componentes $\mathrm{U}$ e $\mathrm{V}$ pelo MYNN2.5. Isso é demonstrado aqui através da comparação entre diferentes simulações numéricas e dados tomados in situ através de sensores instalados numa torre 
micrometeorológica. As diferentes simulações são realizadas usando três grades aninhadas e condições de contorno impostas pelas análises GFS-FNL.

O presente estudo oferece resultados inéditos observacionais tomados pelo PROANTAR em conjunto com o Comitê Polar Espanhol na Ilha Deception, um ambiente inóspito que, além das restrições esperadas para a atividade humana no ambiente antártico, é um vulcão ativo com atividade geotermal presente. Isso torna a Ilha, um verdadeiro laboratório para investigação polar, ao mesmo tempo, em que aumenta o grau de incerteza quanto à boa previsão de tempo local. Os diferentes esquemas de CLP e microfísica testados aqui para o WRF são a primeira tentativa em estabelecer critérios para a operação de um WRF Polar Brasileiro.

Para a temperatura do ar a $2 \mathrm{~m}$ da superfície os diferentes experimentos simulados de CLP, em ambos os esquemas microfísicos, resultam num ciclo diário de menor amplitude do que aquela vista nos dados observados. A sensibilidade entre os esquemas é em média menor que $1{ }^{\circ} \mathrm{C}$. Essa baixa sensibilidade possivelmente se deve à influência da TSM no interior da Ilha Deception, e também a diferente capacidade que eles têm de reproduzir a nebulosidade estratiforme. Essa nebulosidade não é bem representada nos esquemas MYJ e QNSE, ocasionando erros nas radiações de ondas curta e longa. Na ROC a sensibilidade entre os esquemas de CLP é maior para os dias com nebulosidade (20 e 22) do que para o dia de céu claro (dia 21). Para o dia de céu claro uma boa previsão depende fortemente do esquema microfísico utilizado e não dos esquemas de CLP. Neste dia a diferença entre os esquemas microfísicos (WSM3 e THOMPSON) é de $100 \mathrm{~W} / \mathrm{m}^{2}$, enquanto a sensibilidade entre os esquemas de CLP é muito menor entre zero a $15 \mathrm{~W} / \mathrm{m}^{2}$. Para a ROL a sensibilidade entre os esquemas microfísicos, no dia 21 , é muito pequena, assim como para os esquemas de CLP escolhidos. No dia 21, as simulações para a ROL subestimam os dados observados entre $30 \mathrm{~W} / \mathrm{m}^{2}$ e $100 \mathrm{~W} / \mathrm{m}^{2}$. No dia 22 (com ciclone atuando), o esquema microfísico THOMPSON simula melhor que o WSM3. Os esquemas MYJ e QNSE têm dificuldade em simular nebulosidade estratiforme. O ciclo da PA é mais dependente dos padrões meteorológicos de grande escala, com pequena variabilidade em escala local. Os diferentes esquemas de CLP e microfísicos são qualitativamente semelhantes para a pressão atmosférica e são bem reproduzidos pelo modelo WRF independente dos esquemas a serem utilizados nas previsões.

Para o vento zonal a sensibilidade entre os esquemas de CLP varia em média de 1 a $3 \mathrm{~m} / \mathrm{s}$. Sendo maior entre os esquemas de CLP do que entre os esquemas microfísicos, exceto no experimento de BOULAC. É interessante resaltar que durante a passagem de sistema ciclônico, no esquema microfísico WSM3, a sensibilidade temporal na previsão do aumento dos ventos varia de 3 horas em MYJ e QNSE e de 4 horas nos outros em relação aos dados obser- vados. Já no THOMPSON os esquemas de CLP são semelhantes e todos prevêem este aumento de velocidade com 4 horas de atraso, em relação aos dados observados. Podemos enfatizar que o WSM3, dependendo do esquema de CLP a ser utilizado, é mais indicado para as previsões nestas situações do que o THOMPSON.

$\mathrm{O}$ vento meridional segue a mesma tendência do vento zonal com suavização das flutuações do vento, porém não há atraso nas simulações nos períodos de aumento do vento. A sensibilidade entre os esquemas de CLP varia de 1 a $3 \mathrm{~m} / \mathrm{s}$. Observa-se pouca diferença entre os esquemas microfísicos, exceto para o experimento BOULAC que apresenta maior variabilidade. Os outros esquemas CLP são muito semelhantes independente do esquema microfísico utilizado.

Os coeficientes de correlação entre os dados simulados e reais apresentados aqui são superiores a 0,51 (temperatura do ar), chegando a 0,98 (pressão atmosférica). As simulações são capazes de representar razoavelmente bem o ciclo meteorológico diário dominante na Ilha e, em alguns casos, as flutuações das observações com ou sem retardo de tempo.

\section{Agradecimentos}

Os autores agradecem o apoio financeiro do CNPq/PROANTAR ao projeto INTERCEPTION (556783/2009-3) e ao CsF. Agradecemos também o apoio do Laboratório de Meteorologia e Oceanografia por Satélites (LAMOS) do Centro Regional Sul de Pesquisas Espaciais do INPE.

\section{Referências}

BOUGEAULT, P.; LACARRÈRE, P. Parameterization of orographic induced turbulence in a mesobeta scale model. Monthly Weather Review, v. 117, p. 1872-1890, 1989.

BRETHERTON, C.S.; UTTAL, T.; FAIRALL, C.W.; YUTER, S.E.; WELLER, R.A.; BAUMGARDNER, D.; COMSTOCK, K.; WOOD, R.; RAGA, G.B. The Epic 2001 Stratocumulus Study. Bulletin of the American Meteorological Society, v. 85, p. 967-977, 2004.

BROMWICH, D.H.; CASSANO, J.J. Recommendations to the National Science Foundation from the Antarctic Weather Forecasting Workshop. BPRC Misc. Series M-420, p. 48, 2000. [Available from Byrd Polar Research Center, The Ohio State University, 1090 Carmack Rd., Columbus, OH, 43210-1002.]

BROMWICH, D.H.; HINES, K.M.; BAI L.-S. Developments and testing of Polar Weather Research and Forecasting model: 2. Arctic Ocean. Journal Geophysical Research Atmospheres, v. 114, n. 08121, p. 1-22, 2009.

BROMWICH, D.H.; OTIENO, F.O.; HINES, K.M.; MANNING, K.W.; SHILO, E. A comprehensive evaluation of Polar WRF forecast performance in the Antarctic. Journal Geophysical Research Atmospheres, v. 118, p. 274-292, 2013.

CASSANO, J.J. Performance of the Weather Research and Forecasting Model for month-long Pan-Artic simulations. Monthly Weather Review, v. 139, p. 3469-3488, 2011. 
CHENG, W.Y.Y.; LIU, Y.; LIU, Y.; ZHANG, Y.; MAHONEY, W.; WARNER, T. The impact of model physics on numerical wind forecasts. Renewable Energy, v. 55, p. 347-356, 2013.

DONG, X.; MACE, G.G. Arctic stratus cloud properties and radiative forcing derived from ground-based data collected at Barrow, Alaska. Journal Climate, v. 16, p. 445-461, 2003.

DONLON, C.J.; NIGHTINGALE, T.J.; SHEASBY, T.; TURNER, J.; ROBINSON, I.S.; EMERY, W.J. Implications of the oceanic thermal skin temperature deviation at high wind speed. Geophysical Research Letters, v. 26, n. 16, p. 2505-2508, 1999.

GIBBS, J.A.; FEDOROVICH, E.; VAN EIJK, A.M.J. Evaluating Weather Research and Forecasting (WRF) Model Predictions of Turbulent Flow Parameters in a Dry Convective Boundary Layer. Journal Applied Meteorology Climatology, v. 50, p. 2429-2444, 2011.

HINES, K.M.; BROMWICH, D.H. Development and testing of Polar WRF. Part I: Greenland Ice Sheet meteorology. Monthly Weather Review, v. 136, p. 1971-1989, 2008.

HINES, K.M.; BROMWICH, D.H.; BAI, L.-S.; BARLAGE, M.; SLATER, A.G. Development and Testing of Polar WRF. Part III: Arctic Land. Journal of Climate, v. 24, p. 26-48, 2011.

HONG, S.-Y.; DUDHIA, J.; CHEN, S.-H. A Revised Approach to Ice Microphysical Processes for the Bulk Parameterization of Clouds and Precipitation. Monthly Weather Review, v. 132, p. 103-120, 2004.

JANJIC, Z. Nonsingular implementation of the Mellor Yamada level 2.5 scheme in the NCEP Meso model. NCEP Office Note 437, p. 60, 2002.

LAINE, V. Antarctic ice sheet and sea ice regional albedo and temperature change, 1981-2000, from AVHRR Polar Pathfinder data. Remote Sensing of Environment, v. 112, p. 646-653, 2008.

MONAGHAN, A.J.; BROMWICH, D.H.; POWERS, J.G.; MANNING, K.W. The climate of the McMurdo, Antarctica, region as represented by one year of forecasts from the Antarctic Mesoscale Prediction System. Journal of Climate, v. 18, p. 1174-1189, 2005.

NAKANISHI, M.; NIINO, H. An improved Mellor-Yamada level-3 model with condensation physics: Its design and verification. Boundary-Layer Meteorology, v. 112, p. 1-31, 2004.

NAKANISHI, M.; NIINO, H. An Improved Mellor Yamada Level-3 Model: Its Numerical Stability and Application to a Regional Prediction of Advection Fog. Boundary-Layer Meteorology, v. 119, p. 397-407, 2006.

PLEIM, J.E.; CHANG, J.S. A non-local closure model for vertical mixing in the convective boundary layer. Atmospheric EnvironmentPart AGeneral Topics, v. 26, p. 965-981, 1992.

POWERS, J.G. Numerical prediction of an Antarctic severe wind event with the Weather Research and Forecasting (WRF)
Model. Monthly Weather Review, v. 135, p. 3134-3157, 2007.

POWERS, J.; MANNING, K.W.; BROMWICH, D.H.; CASSANO, J.J.; CAYETTE, A.M. A decade of Antarctic science support through AMPS. Bulletin of the American Meteorological Society, v. 93, p. 1699-1712, 2012.

POWERS, J.G.; MONAGHAN, A.J.; CAYETTE, A.M.; BROMWICH, D.H.; KUO, Y.-H.; MANNING, K.W. Real-time mesoscale modeling over Antarctica. American Meteorological Society, BAMS, p. 1533-1545, 2003.

RUHL, H.A.; HASTINGS, P.A.; ZARUBICK, L.A.; JENSEN, R.M.; ZDZITOWIECKI, K. Fish populations of Port Foster, Deception Island, Antarctica and vicinity. Deep-Sea Research II, v. 50, p. 1843-1858, 2003.

SHIN, H.; HONG, S. Intercomparison of Planetary BoundaryLayer Parametrizations in the WRF Model for a Single Day from CASES-99. Boundary-Layer Meteorology, v. 139, p. 261-281, 2011.

SKAMAROCK, W.C.; KLEMP, J.B. A time-split nonhydrostatic atmospheric model for weather research and forecasting applications. Journal of Computational Physics, v. 227, p. 3465-3485, 2008.

SMITH, JR., K.L.; BALDWIN, R.J.; GLATTS, R.C.; CHERESKIN, T.K.; RUHL, H.; LAGUN, V. Weather, ice, and snow conditions at Deception Island, Antarctica: long time-series photographic monitoring. Deep-Sea Research II, v. 50, p. 1649-1664, 2003.

SUKORIANSKY, S.; GALPERIN, B.; STAROSELSKY, I. A quasi normal scale elimination model of turbulent flows with stable stratification. Phys. Fluids, v.17, p. 085107-1085107-28, 2005.

THOMPSON, G.; RASMUSSEN, R.M.; MANNING, K. Explicit forecasts of winter precipitation using an improved bulk microphysics scheme. Part I: Description and sensitivity analysis. Monthly Weather Review, v. 132, p. 519-542, 2004.

WILSON, A.B.; BROMWICH, D.H.; HINES, K.M. Evaluation of Polar WRF forecasts on the Arctic System Reanalysis domain: Surface and upper air analysis. Journal of Geophysical Research, v. 116, p. 1-18, 2011.

YVER, C.E.; GRAVEN, H.D.; LUCAS, D.D.; CAMERONSMITH, P.J.; KEELING, R.F.; WEISS, R.S. Evaluating transport in the WRF model along the California coast. Atmospheric Chemistry and Physics, v. 13, p. 1837-1852, 2013.

ZILITINKEVICH, S.S. Non-local turbulent transport: pollution dispersion aspects of coherent structure of convective flows, Air Pollution III - Air Pollution Theory and Simulation. Computational Mechanics Publications, v. 1, p. 53-60, 1995.

All the contents of this journal, except where otherwise noted, is licensed under a Creative Commons Attribution License CC-BY. 